\title{
La confianza en las virtudes del juez constitucional y la aporía de los principios de autorrestricción judicial
}

\author{
The trust in the virtues of the constitutional judge \\ and the aporia of judicial self-restraint principles
}

\section{Tania Busch Venthur (iD)}

Universidad Andrés Bello, Chile

\begin{abstract}
RESUMEN El problema de la limitación del poder de los jueces constitucionales ha sido mayoritariamente abordado en una perspectiva que este artículo denomina «la confianza en las virtudes». Dentro de esta aproximación, se identifican tres versiones: la que ofrece un modelo de juez constitucional ideal; la que desarrolla herramientas interpretativas para la adjudicación constitucional; y la que propone centrarse en la virtud personal del juez constitucional. Este trabajo sostiene que la aproximación descrita tiene relevancia para la autocomprensión de los jueces constitucionales y la interpretación, pero como mecanismo destinado a la limitación del poder resulta insuficiente. Se concluye que un control efectivo del poder del juez constitucional habrá de apoyarse necesariamente en arreglos institucionales.
\end{abstract}

PALABRAS CLAVE Autorrestricción judicial, deferencia, presunción de constitucionalidad, virtud judicial, cuestiones políticas.

ABSTRACT The problem of the limitation of the power of the constitutional judges has been mainly approached in a perspective that this article proposes to denominate as of «confidence in the virtues». Within this approach, three versions are identified: the one that offers a model of an ideal constitutional judge; the one that develops interpretive tools for the constitutional adjudication; and the one that proposes to focus on the personal virtue of the constitutional judge. This paper argues that the approach described is relevant to the self-understanding of constitutional judges and interpretation, but as a mechanism designed to limit power is insufficient. Concludes that effective control of the power of the constitutional judge will necessarily rely on institutional arrangements.

KEYWORDS Judicial self-restraint, deference, presumption of constitutionality, judicial virtue, political questions. 


\section{Generalidades}

La especificidad de la jurisdicción constitucional, a medio camino entre lo político y lo jurídico, plantea desafíos importantes con respecto a cómo ha de perfilarse el rol del juez constitucional dentro del sistema democrático. Pese a las relevantes consecuencias que para la vida social y política importan las decisiones de los jueces constitucionales, el control y régimen de responsabilidad de estos magistrados es un ámbito poco estudiado.

El desarrollo de la literatura no parece responder a la necesidad de abordar el problema del control del juez constitucional. La mayor parte de las obras que se refieren al tema tratan sobre la crítica de la falta de legitimidad del control constitucional, o denuncian el amplio margen de acción que el texto constitucional tiene frente a la creación jurídica. Los estudios suelen referirse a las cortes constitucionales como órgano, y poco se ha escrito sobre el control que debe recaer en los magistrados que ejercen la jurisdicción constitucional.

En este trabajo pretendo identificar de qué modo se ha abordado el problema de la limitación del poder de los jueces constitucionales. Sostendré que el abordaje ha sido predominantemente normativo, con una perspectiva que he denominado «de la confianza en las virtudes». Identificaré y desarrollaré tres versiones de esta perspectiva, con especial atención a la recepción de estas en nuestro medio. Finalmente, sostendré que, pese a la utilidad que puede presentar la perspectiva de la confianza en las virtudes y el desarrollo de un modelo de juez constitucional ideal, como herramienta para el control del poder del juez constitucional, resulta insuficiente.

\section{La aproximación de la «confianza en las virtudes» como modo de enfrentar el problema del control del juez constitucional}

En materia de jurisdicción constitucional, el esfuerzo por la limitación del poder de los jueces se ha situado en el ámbito de la teoría de la interpretación y argumentación jurídica, desarrollando teorías o principios que ofrezcan al juez constitucional un modelo a seguir para el momento de la adjudicación en materia constitucional. Asimismo, se observa una tendencia a la descripción de un tipo ideal del juez constitucional, señalando un catálogo de virtudes y valores a realizar por este.

A través de pautas y modelos normativos, se busca impedir que el juez constitucional, en el ejercicio de su labor, extienda su competencia invadiendo ámbitos reservados tradicionalmente a los poderes electos: legislativo y ejecutivo. Se trata de un esfuerzo por persuadir al juez constitucional para que ejerza su función virtuosamente, ${ }^{1}$ lo que estas pautas o modelos normativos identifican con concebir, de forma restrictiva, su lugar en el sistema democrático institucional y el correcto modo de ejercicio de sus atribuciones.

1. Los destacados son nuestros. 
La aproximación descrita importa una perspectiva normativa, sea porque se refiere a la persona del juez constitucional (si la persona del juez es virtuosa o desarrolla virtudes entonces juzgará virtuosamente), sea porque se refiere a la forma virtuosa de realizar la decisión (ejercicio de las llamadas virtudes pasivas).

Propongo llamar a esta forma de aproximarse al problema del control del juez constitucional la perspectiva de la confianza en las virtudes, utilizando el término virtud en un sentido laxo. Agrupo, en este concepto, a las aproximaciones al tratamiento del juez constitucional que tienen como característica central su normatividad, es decir, que se caracterizan por ofrecer pautas de conducta virtuosa sin prestar demasiada atención a concreciones institucionales que las hagan efectivas. Se trata de descripciones de la virtud en cuyo desarrollo parecen bastarse a sí mismas, en tanto que no avanzan en instituciones que velen por su concreción en el plano fáctico, organizando el poder de tal modo que dichas virtudes sean impulsadas o fomentadas por un arreglo institucional concreto.

Se trata de una perspectiva que confía en que el juez constitucional adoptará los modelos normativos ofrecidos. Esto, no obstante, no puede considerarse control. Un modelo normativo o ideal de virtud es, a fin de cuentas, una «sugerencia» a los jueces que estos podrán o no tomar. Si bien los esfuerzos de la teoría y filosofía del derecho han sido siempre indispensables para que la teoría constitucional pudiera enfrentar los problemas relacionados con la interpretación y la aplicación de la Constitución, estos se centran principalmente en el aspecto subjetivo de la actividad judicial y en la dimensión normativa de los postulados teóricos que debieran orientar la tarea decisoria del juez. Es decir, son esfuerzos destinados a saber cómo el juez debe decidir en los denominados casos difíciles (Rufino do Vale, 2017: 17). Sin embargo, como advierte Bello Hutt (2017: 5), esta forma de aproximarse a la cuestión nos deja con el problema distinto de encontrar razones para elegir un método de interpretación u otro, ya que «no existe una regla universal preordenando la manera en la que las constituciones han de ser interpretadas».

Para el desarrollo de este trabajo, dentro de la categoría de la confianza en las virtudes, incluiré tres grupos o tipos de trabajos:

- Primero, aquellos que construyen un «catálogo de virtudes» o un «modelo de juez constitucional ideal».

- Segundo, los que proponen teorías o principios de interpretación constitucional orientados a que el ejercicio de la labor del juez constitucional se realice autorestrictivamente, lo que se identifica con un ejercicio virtuoso de la jurisdicción constitucional.

- Tercero, aquellos que se basan en la teoría de la decisión judicial centrada en las virtudes.

En las páginas siguientes, desarrollaré esta perspectiva explicando las diversas presentaciones que adopta e intentaré dar algunas luces sobre sus posibilidades y limitaciones. 


\section{El catálogo de virtudes y el modelo de juez constitucional ideal (o los jueces constitucionales dando testimonio)}

Una forma en que se aborda la cuestión es a través de trabajos que construyen un modelo ideal de juez constitucional o un catálogo de virtudes a realizar por este. Dicho desarrollo doctrinal se fundamenta, por una parte, en los requisitos que los diversos ordenamientos consideran para el cargo, pero también, y de un modo importante, en la experiencia de los académicos que han desempeñado esta magistratura. Se observa que usualmente el tema es abordado por los propios jueces o exjueces constitucionales que escriben dando testimonio de su labor y experiencia en la magistratura constitucional (Zagrebelsky, 2008: 12; Barak, 2006: 315; Cea Egaña, 2010: 449).²

El modo de enfrentarlo ha sido desarrollar cuál ha de ser el perfil de dicha magistratura y los principios que deben dirigir su actuación, configurar un «modelo ideal» de juez constitucional, abundante en declaraciones de principios y valores que el juez constitucional ha de realizar (Nogueira Alcalá, 2004: 88; Cea Egaña, 2003: 2 y 2006: 183 y ss.; Zúñiga Urbina, 2010: 266; Landa, 2004: 147; Álvarez Miranda y Canales Cama, 2009: 2 y 15; Azuela Güitrón, 2009: 29; Rohrmoser Valdeavellano, 2002: 346; Mellinghoff, 2011: 498), ${ }^{3}$ que la doctrina identifica como los valores del constitucionalismo.

2. Muchos escriben desde el testimonio y lo declaran expresamente en sus trabajos sobre la materia. Así, por ejemplo, Zagrebelsky, en el prefacio de su libro Principios y votos, expresa: «el material que alimenta estas reflexiones no es por ello principalmente el que encontramos en recopilaciones legislativas. Es más bien el recuerdo de una experiencia que he tenido la fortuna de vivir junto a los colegas con los que he compartido el trabajo y la fatiga, las jornadas y las tensiones de nueve años». Aharon Barak, juez de la Corte Suprema de Israel, en The judge in a democracy señala: «Esta es mi aproximación a mi rol como juez. Llevo este enfoque conmigo todos los días a la sala de la corte. Este es mi enfoque cuando dicto sentencia. Es un enfoque en cuyo centro se encuentran los valores de una democracia; es un enfoque en cuyo centro se encuentra el ser humano, creado a imagen de Dios; es un enfoque que ve el rol de la judicatura como un servicio, no como un poder». La traducción es nuestra. También José Luis Cea Egaña, en su trabajo «El juez constitucional en Chile», hace una declaración similar: «quiero, en otras palabras, presentar una síntesis de lo visto, a veces padecido, y en otras ocasiones gozado como juez constitucional. Igual que el espíritu, que es íntimo, así también deseo decir que algo de confesión, más que de simple reconocimiento, caracteriza esta exposición».

3. Así, a modo de ejemplo, Humberto Nogueira desarrolla los «valores, principios y responsabilidades que el constitucionalismo contemporáneo exigen al juez constitucional»; José Luis Cea Egaña, expresidente del Tribunal Constitucional chileno, trata sobre el perfil axiológico ideal del juez constitucional y de su imagen ideal, arquetipo y valores de este. En un sentido distinto, Francisco Zúñiga Urbina postula que, en el plano valórico, el Tribunal Constitucional «debe ser heredero de una concepción secular e ilustrada de derecho, que separa derecho y moral, y a partir de una idea de derecho de raíz kantiana entienda que el orden social de la libertad exige que el derecho sea "mínimo ético" y no máximo ético». En el ámbito latinoamericano, Cesar Landa, expresidente del Tribunal Constitucional peruano, se refiere al perfil del magistrado constitucional y trata las condiciones de imparcialidad y especialización que deben poseer y sus cualidades personales y humanas. Otro ministro del Tribunal Constitucional peruano que desarrolla el tema es Ernesto Álvarez, quien señala que la institucionalidad de la justicia constitucional debe fortalecer «los procedimientos de elección de sus miembros, de forma que la actual selección culmine con designaciones de juristas de comprobada conducta institucional y cívica» y que «la vida del tribunal depende 
Particularmente ilustrativo, en este sentido, es el documento titulado «El juez constitucional», resultante de la V Conferencia Iberoamericana de Justicia Constitucional, en que bajo el título de «arquetipo realizable» se señala que:

Ser juez constitucional supone poner a prueba, en todas las decisiones que adopta, la resolución y la prudencia, el coraje y la independencia, la ecuanimidad y la ciencia o la técnica, en fin, la innovación y la experiencia. De esas cualidades debe dar siempre testimonio, pero que llega a ser ejemplar en las prevenciones y disidencias (Conferencia Iberoamericana de Justicia Constitucional, 2006: 33).

Sin embargo, como modelo ideal que es, su correlato con la realidad es imperfecto: es improbable que todo juez constitucional se comporte siempre de acuerdo con el modelo. Si bien es posible sostener que las virtudes del juez constitucional ideal pueden verificarse frecuentemente en la práctica, «frecuentemente» no es suficiente para que las propuestas de control del juez constitucional se satisfagan con una enumeración de principios y valores a realizar, y recomendaciones de buen comportamiento. Como abordaje del problema del control del juez constitucional, parece un poco ingenuo confiar en que la elaboración de un modelo ideal que se presenta al juez constitucional como pauta normativa sea suficiente.

Ahora bien, esto no significa que la elaboración de este catálogo de virtudes carezca de relevancia y consecuencias. Esta construcción resulta de importancia en tanto devela cómo los jueces constitucionales han entendido su labor, e incide en la forma en que se diseña su estatuto. Quiero decir que el modelo ideal de juez constitucional que se construya incidirá en el modo en que se diseñen los arreglos institucionales de control.

de ellos, de sus talentos, experiencias y puntos de vista individuales», y refiriéndose al perfil de juez constitucional deseable, señala como relevantes para el ejercicio de la magistratura constitucional, entre otras, «buscar la justicia y equidad en todas las situaciones en las que interviene» $\mathrm{y}$ «estar comprometido con los derechos humanos, la democracia y el Estado social y democrático de derecho». Por su parte, el mexicano Mariano Azuela, expresidente de la Suprema Corte de Justicia de la Nación, se refiere también al perfil del juez constitucional y las cualidades que deben caracterizarlo, así como los valores y principios que deben trazar las directrices esenciales para el adecuado desempeño de este. En el mismo sentido, el expresidente de la Corte de Constitucionalidad de Guatemala, Alejandro Maldonado Aguirre, citado por Rohrmoser Valdeavellano menciona: «los jueces de lo constitucional deben ser moralmente fuertes para cumplir, afrontando cualquier riesgo, su función primordial de defensa del orden constitucional, y también para domeñar sus propias tentaciones que los impulsen al activismo judicial. De los diferentes sistemas de control, el adoptado por nuestra Constitución implica que las controversias cargadamente políticas que se someten a su juicio deben resolverse jurídicamente, aun cuando la ambigüedad y la generalidad de los textos concedan un apreciable margen de valoración. El juez debe resolver conforme el sentido de la justicia y de buena fe, despolitizando la decisión y recordando que, mientras se encuentre vistiendo la toga, no puede contaminar su juicio con sus creencias partidaristas, ideológicas, de clase o de interés particular». Por su parte, Mellinghoff, juez del Tribunal Constitucional Federal alemán, señala: «el ejercicio de las enormes atribuciones de poder de las cuales puedan gozar los jueces del tribunal Constitucional requiere, además, que actúen con responsabilidad personal, integridad moral y respeto por la ética judicial y profesional. Los jueces serán merecedores de la confianza de la población si adoptan los estándares más altos en el ejercicio de su función y actúan de conformidad con las virtudes de un juez». Los destacados son nuestros. 
Como indica Courtis (2006: 363), el derecho, para regular una parcela de la realidad, parte desde la normativización de una situación ideal-típica, de una «imagen» que se adopta como modelo para diseñar regulaciones, que frecuentemente es el resultado de un proceso de «selección», de «normalización» en el sentido de transformación de un parámetro, en un referente, en una regla de rasgos que se abstraen de una situación determinada de la vida social. Así, «la selección de una situación ideal-típica o "imagen” constituye, como es evidente, una manifestación ideológica, ya que forja justamente la expresión de una concepción o punto de vista particular de observación y valoración del mundo» (Courtis, 2006: 363).

El modelo normativo de juez constitucional que se ha construido por la doctrina, se ve determinado por el constitucionalismo como ideología y por el contexto actual en que este es tratado, el auge del neoconstitucionalismo, que implica una confianza importante en la judicatura. Este contexto tiene implicancias en el modo en que se diseñan las instituciones de control y en la autocomprensión de los jueces constitucionales.

Ahora bien, esto plantea un problema, y es que la medida en que se avanza en la profundización de este modelo normativo es inversamente proporcional al avance en un modelo institucional. De algún modo, el desarrollo del modelo normativo conduce a hacer creer que el juez constitucional, por el hecho de ser tal, cumple con el catálogo de virtudes que establece el modelo normativo para el juez constitucional ideal, y hace que se relaje o diluya la atención con respecto a los mecanismos institucionales de control, que tiene como foco el juez constitucional real.

Una perspectiva que aborda el tema desde un catálogo más o menos determinado de valores a realizar o elaboración de modelos ideales resulta insuficiente. Este juez constitucional ideal debe concretarse en instituciones que cautelen que el juez constitucional real se acerque a la realización de estas pautas.

\section{Las «virtudes pasivas» y la doctrina de las cuestiones políticas no justiciables (o el juez constitucional autolimitándose)}

Tomaré la expresión «virtudes pasivas», acuñada por Bickel (1961), para designar en este trabajo a la idea general de que el juez constitucional ha de autolimitarse en la tarea de la adjudicación constitucional y, de este modo, controlar su propio poder. El ejercicio de las virtudes pasis recurrir a diversas doctrinas, principios de interpretación y teorías sobre la competencia que tienen en común buscar que el juez constitucional sea cauteloso en el desarrollo de su actividad, sin extender sus atribuciones invadiendo competencias de otros poderes u órganos contemplados en la Constitución.

Entre estas teorías, creadas por la doctrina y los propios jueces constitucionales, se encuentra la deferencia razonada, la autorrestricción o judicial self-restraint, el principio de corrección funcional y la presunción de constitucionalidad de los actos del legislador. También agrego en este apartado a la doctrina de la no justiciabilidad de las llamadas «cuestiones políticas», que se presenta como una teoría sobre la competencia y no como una virtud a realizar por el juez constitucional. Pese a lo anterior, la incor- 
poro toda vez que el resultado de su aplicación implicará la autolimitación del juez constitucional.

El fundamento común de todas estas doctrinas, teorías y principios es el respeto al principio de separación de poderes, pilar fundacional del constitucionalismo (Blanco Valdés, 1994; Díaz Bravo, 2012). ${ }^{4}$ Si bien hoy la teoría de la separación de poderes no resulta adecuada como descripción del modo en que las diversas funciones estatales se estructuran, su dimensión normativa permanece vigente, determinando la forma en que cada órgano comprende su propio rol dentro del sistema institucional, como asimismo las expectativas creadas con respecto a este (Stone Sweet, 2000: 130). ${ }^{5}$ Sobre esto, Ignacio Colombo Murúa (2012: 32 y ss.) explica que el sujeto juez tiene su razón de ser asentada ineludiblemente en el principio republicano de separación de poderes. Este ha recibido una formación jurídica determinada transmitida a través de la tradición, en donde el principio de separación de poderes aparece incorporado a las reflexiones doctrinarias y al diseño institucional imperante. Como quien interpreta lo hace siempre desde un bagaje teórico determinado, el principio de división de poderes no se disolverá, sino que estará presente en la tarea jurisprudencial. Expone Colombo Murúa que el juez que dicta sentencia debe primero comprenderse a sí mismo, esto es, entender por qué está facultado a decidir y cuál es su ubicación personal e institucional. Además, la tarea interpretativa del juez se realiza desde una precomprensión determinada, conformada primordialmente por su formación jurídico-constitucional, asentada ineludiblemente en el principio de separación de poderes y que así se explica que los jueces esgriman reiteradamente la división de poderes como un argumento, incluso, para autorrestringir sus potestades.

Las doctrinas de autolimitación y la exhortación al ejercicio de virtudes pasivas se explican como una reacción frente a la disrupción que importa para jueces constitucionales y constitucionalistas el observar que la justicia constitucional, particularmente los tribunales constitucionales, detentan un poder que es, a su modo político y de legislador "positivo», para usar la terminología kelseniana. Se trata de un poder que no se corresponde con el modelo normativo que tenemos del rol que deben cumplir los jueces en un sistema democrático, que se sigue de la referida dimensión prescriptiva del principio de separación de poderes. Como consecuencia de lo expuesto, es que se considere que un ejercicio virtuoso de las competencias de la judicatura constitucional importa ejercerlas restrictivamente y, de este modo, ajustarlas lo más posible a lo es-

4. Para más información, véase a los autores referenciados en relación con el desarrollo del principio de separación de poderes.

5. «La doctrina de la separación de poderes sostiene la teoría del Estado, reflejando, pero también condicionando, cómo debe ser entendida y evaluada la legitimidad política. Esta doctrina es un constructo profundamente normativo. Leído en clave descriptiva, como sistema de reglas, tiene por objeto modelar la relación entre estructuras y funciones en un sistema complejo de gobierno. Leída en clave prescriptiva, como un conjunto de expectativas idealizadas con respecto a cómo estas estructuras y funciones deben relacionarse, proporciona estándares para evaluar la pertinencia de la conducta oficial.». La traducción es nuestra. 
perado de los jueces conforme a la separación de los poderes, que concibe a los jueces como un poder, en cierto modo, nulo (en referencia a Montesquieu).

Pese a que cuestiones políticas, presunción de constitucionalidad o deferencia son conceptos conocidos, nombrados y utilizados por la doctrina e invocados como argumento en las sentencias constitucionales, no existe claridad con respecto a su delimitación o ámbito de aplicación. Su tratamiento doctrinario es, en general, discreto. Para comenzar, no siempre se les entiende como teorías o conceptos diferenciados: en ocasiones, los términos deferencia, autorrestricción o presunción de constitucionalidad son utilizados como sinónimos y, a veces, se les menciona significando fenómenos distintos. En otros casos, deferencia es el género o el todo y la presunción de constitucionalidad un elemento o manifestación de la deferencia. Otros trabajos consideran la doctrina de las cuestiones políticas como una manifestación o consecuencia de la autorrestricción, o a veces se estudia corrección funcional o presunción de constitucionalidad de la ley como cuestiones separadas de la autorrestricción o la deferencia.

Tampoco hay demasiada claridad en cuanto a su función o categoría jurídica. Se les ha denominado de diversas formas: virtudes, mecanismos, actitudes, pero su denominación más frecuente es la de principios. Esto remite a la discusión, nada sencilla, sobre el concepto de principios, su uso y función en el derecho (Carbonell, Coloma y Letelier, 2011: IV). ${ }^{6}$ En todo caso, no es un problema cuya discusión atraiga la atención con respecto a conceptos como la autorrestricción o la presunción de constitucionalidad, toda vez que, en general, el problema asociado a la categoría jurídica de "principio» tiene que ver con una ampliación de las facultades del juez, ${ }^{7}$ y los principios en estudio implican precisamente el efecto contrario. De cualquier modo, esto no elimina el problema de la vaguedad conceptual ni de la categoría "principio», ni del contenido o significado específico de la autorrestricción judicial, de la presunción de constitucionalidad, corrección funcional o cualquier otro mecanismo (para emplear un término aún más amplio) de los que se proponen como herramientas para domesticar el poder del juez constitucional. Por último, no se ocupan los autores en justificar de dónde extraen estos principios, o si lo hacen, utilizan formas tan vagas como «de la naturaleza misma del régimen democrático» (Zapata Larraín, 2008: 229). Se trata, en cualquier caso, de categorías que no encuentran fundamento dogmático explícito en el texto de la Constitución.

En los párrafos siguientes expondré los elementos centrales de las teorías, doctrinas y principios más importantes que apuntan a la autolimitación de la acción del juez constitucional.

6. Como indican Carbonell, Coloma y Letelier, la ausencia de comprensión intersubjetiva de los contenidos de los principios transforma su aplicación en una cuestión fuertemente dependiente del decisor (paradigmáticamente el juez), con el peligro de la falta de sincronía entre este y la sociedad. El alzamiento de las normas de principio por sobre las reglas aprobadas democráticamente altera las relaciones de legitimación pública y distorsiona los mecanismos de equilibrios de poderes.

7. En contraste, y a modo de ejemplo, piénsese en los problemas y discusiones que han traído aparejados conceptos elevados a la categoría de principios como «razonabilidad», «proporcionalidad», «principio protector» en materia laboral, o la utilización del parámetro de la «buena fe». 
La denominación más genérica de esta idea es el concepto de autorrestricción judicial o self-restraint. La cuestión con respecto a la deferencia que debe la judicatura a otros poderes que toman decisiones políticas interpretando la Constitución, se remonta al tiempo de la discusión sobre la aprobación de la Constitución norteamericana y el origen de la revisión judicial (Kramer, 2011; 2012: 622). El primer trabajo que expone sistemáticamente una teoría para la autolimitación del juez constitucional aparece en 1893, con el artículo de James Thayer titulado «The origin and scope of the american doctrine of constitutional law». No obstante, este afirma expresamente: «no estoy exponiendo una doctrina nueva, sino intentando reafirmar más exacta y verdaderamente una doctrina ya admitida» (Thayer, 1893: 155). ${ }^{8}$ En ese sentido, postula que los jueces solo han de declarar la inconstitucionalidad cuando razonablemente no pueda sino concluirse que la ley es contraria a la Constitución:

Solo pueden las cortes desestimar una ley cuando aquellos que tienen derecho a hacer las leyes no solo han cometido un error, sino que el error debe ser prístino, de modo que la cuestión no quede abierta a un debate racional. Este es el estándar al que deben someter las cortes a los actos del legislativo. Este es el test que deben aplicar, no la opinión de los jueces con respecto a su constitucionalidad, sino cuál la interpretación que se le puede permitir a otra rama a la que la Constitución ha entregado la función de realizarla. Esta regla reconoce que, habiendo considerado las enormes y complejas exigencias que despliega el gobierno, las que pueden parecer inconstitucionales a un hombre, o a un grupo de hombres, puede no parecerle así a otros. Que la Constitución usualmente admite diferentes interpretaciones; que frecuentemente existe un rango para la elección y el juicio; que en estos casos la Constitución no impone al legislador una opción específica, sino que deja abierto este rango de posibilidades; y que cualquier opción racional es constitucional (Thayer, 1893: 144).

La pregunta definitiva, sostiene, no radica en cuál es el verdadero significado de la Constitución, sino si la legislación es o no sostenible (Thayer, 1893: 150). ${ }^{9}$ El texto de Thayer también es considerado como la primera formulación de la presunción de constitucionalidad y de la doctrina de las cuestiones políticas, aunque ninguno de estos términos o conceptos es utilizado por el autor. Esto da cuenta de hasta qué punto se trata de conceptos imbricados.

Definir autorrestricción judicial resulta una tarea compleja. Puede indicarse que consiste en la autolimitación que los tribunales deben reconocerse, de manera que no conviertan en letra muerta la actividad de los otros órganos de poder, e implica o presupone un reconocimiento de la amplitud y de los alcances de las facultades que residen en ella por el hecho de ser la justicia constitucional la depositaria de la interpretación constitucional (Caballero, 2010: 429, número 47). Posner (2012: 520) ha calificado al

8. Thayer, en su artículo, reconstruye la idea de la deferencia a través de citar opiniones de jueces y juristas norteamericanos que llegan incluso tan atrás como 1787.

9. La traducción es nuestra. 
término como un camaleón, al cual se le han asignado diversos significados, ${ }^{10}$ siendo el más relevante para este trabajo lo que este autor denomina constitutional restraint (Posner, 2012: 521), señalando con esto la actitud de jueces altamente reacios a declarar la inconstitucionalidad de un acto del legislativo o ejecutivo. En su trabajo titulado «Rise and fall of judicial self-restraint» realiza un recorrido de la teoría a través de la exposición de los postulados de Thayer y los exponentes más relevantes de lo que denomina la escuela thayeriana: Holmes, Brandeis, Franckfurter y Bickel. Luego, expone el declive o desvanecimiento de la teoría de la autorrestricción (Posner, 2012: 535), ${ }^{11}$ explicando que el thayerianismo se abandonó tanto en la academia como en la práctica judicial. Explica este abandono o declive en la academia por la aparición y alza de teorías normativas sobre como «decidir correctamente» una cuestión constitucional..$^{12}$ En cuanto a la práctica judicial, vincula su abandono al activismo de la Corte Warren. Es particularmente interesante la afirmación de Posner con respecto a que ni los jueces que se consideran los exponentes más importantes de esta doctrina manejaron el self-restraint de manera uniforme en todos los casos, y cita sentencias o votos minoritarios con posiciones que podrían calificarse de activistas, lo que da cuenta de lo maleable que es el concepto.

Entre nosotros, la autorrestricción es tratada por Carlos Carmona Santander, quien señala:

Cuando el Tribunal puede imponerse restricciones a sí mismo, hablamos de autorrestricciones. El autocontrol es más que un mero sentido de prudencia o de cautela en el ejercicio de sus competencias. El autocontrol implica que el Tribunal es consciente de sus atribuciones y de lo que el ejercicio de ellas trae aparejado. Ello no significa que la consideración de los efectos de sus resoluciones pueda determinar inequívocamente sus decisiones. No es tampoco una renuncia o abdicación de sus potestades. Se trata más bien de ejercerlas insertas en un sistema, donde hay otros controles y otros órganos elegidos por la gente para tomar las grandes decisiones. El Tribunal no puede sustituir al legislador, porque eso implicaría alterar la representación que la sociedad se da y cerrar espacio a la deliberación. En ese sentido, no puede modificar el equilibrio de poderes que la Constitución diseña. El Tribunal no puede perder de vista que es un órgano del Estado. Por lo mismo, sus potestades son expresas y otorgadas; y en la interpretación de la Constitución, no puede convertirse en un poder constituyente.

10. Los más serios, señala, son: i) autorrestricción como formalismo (los jueces aplican la ley, no la crean); ii) autorrestricción como la consideración de una extensa variedad de materias como de competencia de otros órganos; y iii) lo que denomina constitutional restraint.

11. Señala Posner: «Las modernas teorías constitucionales, ya sea el originalismo de Bork o Scalia, el textualismo de Easterbrook, el refuerzo de la representación de Ely o la libertad activa de Breyer, o la Constitución como common law, o la Constitución viva, o la lectura moral de la Constitución, o el libertarianismo, o la Constitución en el exilio, o cualquier otra (incluyendo el minimalismo, pese a sus afinidades superficiales con el thayerianismo), están diseñadas para decirle a los jueces, particularmente a los justices de la Corte Suprema, cómo decidir de manera correcta antes que simplemente de un modo sensible o prudente».

12. Originalismo, textualismo, Constitución viva, lectura moral, refuerzo de la representación, etcétera. 
Tampoco puede perder de vista que hay otros actores en el control de constitucionalidad (Carmona Santander, 2012: 113).

Analizando la jurisprudencia, señala que existen varias manifestaciones de la autorrestricción en nuestro Tribunal Constitucional (Carmona Santander, 2012: 114 y ss.). Primero, existen áreas con respecto a las cuales este se inhibe de conocer por considerar que exceden sus atribuciones: las relativas a las cuestiones de hecho, de legalidad y de mérito. Segundo, se manifiesta la autorrestricción a través de la utilización de criterios de interpretación como la presunción de constitucionalidad y el principio de interpretación conforme. Como tercera manifestación, señala al método de análisis que utiliza el tribunal para resolver, considerando los precedentes en sus decisiones, los test que emplea y la fundamentación de sus sentencias. Concluye afirmando que «el Tribunal Constitucional [chileno] tiene instrumentos que revelan que puede actuar con autorrestricción en el ejercicio de sus funciones» y que, mediante la autorrestricción, el Tribunal puede ayudar a que su tarea no solo se legitime, sino que también contribuya, o al menos no entorpezca el logro de los objetivos que el pueblo quiere alcanzar en un momento dado, cuando la Constitución da los márgenes para ello. Mientras el Tribunal siga teniendo las atribuciones que le fueron otorgadas, la autorrestricción es la manera en que puede convivir con los poderes públicos, cuyas manifestaciones debe controlar (Carmona Santander, 2012: 124).

En Chile, la idea de la autolimitación de los jueces constitucionales ha sido difundida bajo la expresión «deferencia razonada», acuñada por Patricio Zapata Larraín. Esta designa un modelo ideal de actitud que debe observar el Tribunal Constitucional chileno frente a quienes son objeto de su control, esto es el legislador y el administrador, y consiste en:

Reconocer al órgano responsable de la producción de preceptos jurídicos la potestad de buscar de manera flexible las fórmulas normativas que, ajustadas a la Carta Fundamental, le parezcan necesarias o convenientes para la mejor consecución del bien común (Zapata Larraín, 2008: 229).

La expresión «razonada» hace referencia a que el tribunal debe elaborar categorías de análisis flexibles que le permitan discriminar entre aquellos ámbitos y materias en que cabe reconocer amplia latitud al criterio administrativo o legislativo, de aquellas otras esferas - fundamentalmente regulación y limitación de derechos- en que la deferencia debe conciliarse con el más estricto y riguroso de los controles (Zapata Larraín, 2008: 229).

La deferencia es un modelo normativo de actitud o predisposición que deben observar los poderes públicos, en especial, pero no exclusivamente, el Tribunal Constitucional. Este principio de acción también impone a los poderes de representación democrática el deber de respetar las prerrogativas y resoluciones del Tribunal Constitucional cuando este controla legítimamente la constitucionalidad de sus actos y, en este punto, adquiere una nota o característica distinta de la autorrestricción, que solo 
se postula como una virtud de la jurisdicción, o la presunción de constitucionalidad que opera para la justicia constitucional. A diferencia de otros conceptos similares, la deferencia ha de ser recíproca entre los poderes públicos (Zapata Larraín, 2008: 227). ${ }^{13}$

Zapata Larraín (2008: 229) fundamenta la deferencia en la naturaleza misma del régimen democrático representativo y señala que, en consonancia con el artículo cuarto y quinto de nuestra Constitución que establecen que Chile es una república democrática y que radican el ejercicio de la soberanía en el pueblo, respectivamente, «la dirección de los asuntos públicos corresponde a los representantes libremente elegidos por la ciudadanía y no a jueces sobre los cuales existe poco control político».

Los elementos que constituyen la deferencia razonada son la autonomía del legislador y la presunción de constitucionalidad de los actos del legislador y el administrador. El primer elemento consiste en que corresponde al legislador complementar y detallar las instituciones perfiladas en la Constitución en sus aspectos fundamentales, tarea en la cual la decisión de adoptar una u otra fórmula normativa es resorte del legislador y las apreciaciones de mérito y oportunidad quedan vedadas al examen del Tribunal Constitucional (Zapata Larraín, 2008: 234).

Zapata Larraín (2008: 239) se muestra confiado en las posibilidades de este modelo de actitud ideal o virtuosa, ya que afirma que "constituye un resguardo eficaz contra el activismo jurisdiccional desbordado» y que, atendidas sus «tantas y tan potentes atribuciones», resulta un «necesario antídoto contra la tentación de erigir el Tribunal Constitucional chileno en un "hacedor de justicia"», cuyo riesgo sería que «terminaría transformándose, según sea el caso, en tercera instancia judicial o en tercera cámara legislativa» (Zapata Larraín, 2008: 233). Concluye que deferencia y presunción de constitucionalidad «son valiosos elementos para controlar eventuales arbitrariedades» (Zapata Larraín, 2008: 247).

Siguiendo a Zapata Larraín, Poyanco Bugueño (2013: 89) señala: «a nuestro juicio, la deferencia judicial - bien entendida - puede representar una verdadera garantía de imparcialidad frente a cualquiera de las diversas corrientes sociales o políticas que se impongan en el juego democrático legítimo». Este autor le da la naturaleza de "verdadera garantía» no obstante:

Reconocer lo problemático de la «reputada voluntariedad» con respecto al juez constitucional, reflejada incluso en su propia calificación como «deferencia» autorrestricción y similares, característica que le otorga una volubilidad difícil de evadir desde que implica, en definitiva, una incerteza absoluta en su aplicación» (Poyanco Bugueño, 2013: 97). ${ }^{14}$

13. «El concepto de deferencia encierra dos sentidos complementarios. Significa, en primer lugar, que los poderes públicos se deben a una actitud permanente y recíproca de respeto y cortesía. La deferencia, en segundo lugar, demanda de cada órgano del Estado el reconocimiento y respeto de las esferas competenciales en que las autoridades tienen el derecho a tomar decisiones con relativa autonomía». El destacado es nuestro.

14. Los destacados son del original. 
Destaquemos acá que no se entiende bien cómo puede afirmarse de algo el que sea una "garantía» y, al mismo, afirmar que su aplicación es de «incerteza absoluta».

El concepto postulado por Zapata Larraín ha sido adoptado en Chile por parte de la doctrina (Poyanco Bugueño, 2013; Martínez Estay, 2014; Silva Gallinato, 2014) con singular éxito, llegando a afirmar una autora que la deferencia razonada es «uno de los principios basales de los modernos estados constitucionales de derecho» (Silva Gallinato, 2014: 141). Este modelo también se ha reconocido por el Tribunal Constitucional en su jurisprudencia (Carmona Santander, 2012; Martínez Estay, 2014). ${ }^{15}$ Asimismo, ha sido ampliado por otros autores a la relación entre el Tribunal Constitucional y los jueces ordinarios en materia de inaplicabilidad (Martínez Estay, 2014; 2015).

Generalmente considerada una consecuencia o manifestación de la deferencia o autorrestricción, la presunción de constitucionalidad de la ley impone a quien sostiene que el texto de una ley es inconstitucional, la carga de argumentar convincentemente que existe una incompatibilidad entre la norma que ese texto expresa y el sistema de normas que expresa el texto constitucional. Cualquier duda acerca de la interpretación correcta de uno u otro texto se resolverá a favor del legislador (Ferreres Comella, 1997: 141). Algunos autores hablan, con mayor amplitud, de la presunción de constitucionalidad de los actos del legislador, ya que extienden la presunción de constitucionalidad no solo a la ley, en cuanto norma que ha pasado por el proceso de formación que establece la Constitución al efecto, sino a cualquier otra actuación del poder legislativo que sea de su competencia, como serían, por ejemplo, los proyectos de acuerdo (Silva Gallinato, 2014: 142). ${ }^{16}$

Los actos del legislador en general, y especialmente la ley, están amparados por esta presunción, pues el desarrollo de los postulados constitucionales es tarea que la Constitución encarga al Parlamento. Hesse postula que:

La voluntad y la conducta del legislador democrático gozan de una presunción de constitucionalidad: a él le corresponderá, en primera línea, la conformación jurídica de las relaciones sociales. Al Tribunal Constitucional le está vedado discutir esta primacía al legislador, pues ello acarrearía un desplazamiento de las funciones constitucionalmente encomendadas (Hesse, 1992: 52).

En el desarrollo de sus atribuciones, tanto el ejecutivo como el legislativo interpre-

15. Zapata Larraín señala que, posterior a la reforma de 2015, la deferencia al legislador, «expresada tanto como reticencia a incursionar en el examen de aspectos de mérito y oportunidad o como disposición a preferir, en caso de duda, aquella interpretación de la ley que resulta compatible con la constitución se ha transformado en un elemento central de su actividad jurisdiccional». El destacado es nuestro. Para más información, véase a los autores referenciados para un análisis jurisprudencial de este principio.

16. Sobre esto, véase el análisis de la STC 2646-2014 aplicando el principio de deferencia razonada a los acuerdos efectuado por Silva Gallinato: «Si [el Parlamento] goza de discrecionalidad para determinar tanto el contenido como la oportunidad de la ley, ello también se extiende a diversas actuaciones que puede realizar durante la formación de la ley». 
tan la Constitución (Häberle, 2008a; 2008b). ${ }^{17}$ La interpretación que realiza el Parlamento tiene un valor especial, toda vez que se entiende que el legislativo es la expresión más directa de la soberanía popular, contando con legitimidad democrática originaria al ser sus miembros elegidos directamente por los ciudadanos. Este es el fundamento más difundido de la presunción de constitucionalidad. Con mayor precisión, Ferreres Comella (1997: 163 y ss.) explica que existen diversos argumentos que vienen a justificar esta presunción, dentro de los cuales destacan, primero, el que denomina argumento epistémico, vinculado a la teoría que considera que el proceso democrático es valioso por su tendencia a generar decisiones correctas desde un punto de vista moral, pues, aunque imperfecto, su probabilidad de acierto es mayor que otros procedimientos alternativos; y segundo, el argumento de la igual dignidad política, consistente en que resulta una ofensa a la igual dignidad de las personas el que una ley aprobada democráticamente sea invalidada por un juez cuando la cuestión controvertida admite diversas soluciones en las que personas razonables podrían discrepar. ${ }^{18}$

En cuanto a la fuerza de esta presunción, se advierten diversas posiciones. Autores como Zúñiga Urbina (2010: 270) sostienen que la declaración de inconstitucionalidad debe ser siempre para el Tribunal Constitucional un arma de ultima ratio, pues los actos del poder político en general, y muy especial y destacadamente la ley, están amparados por una sólida presunción de constitucionalidad. Otros autores (Ferreres Comella, 1997; Linares, 2008; Zapata Larraín, 2008) sostienen que esta presunción no es uniforme en su intensidad, admitiendo graduación en su fuerza, o incluso invirtiéndose en determinados supuestos. Se trataría de una presunción material o condicionada y variable. Esto significa que la carga argumentativa de quien sostiene la inconstitucionalidad de la ley puede ser de mayor o menor peso según factores como las circunstancias de aprobación de dicha ley o la materia que se esté regulando. En cuanto a lo primero, la intensidad de la presunción de constitucionalidad varía según su temporalidad: la fuerza de la presunción es mayor si se trata de legislación contemporánea a la revisión de su constitucionalidad y disminuye si se está conociendo de la constitucionalidad de una ley no contemporánea. El fundamento de esto es que, si la justificación principal de la presunción de la ley es su vinculación a la voluntad del pueblo soberano, una ley aprobada hace más de un siglo atrás no puede revisarse de la misma forma que una ley que acaba de entrar en vigencia (Linares, 2008: 148). También habrán de considerarse, para la intensidad de la presunción, las circunstancias fácticas que rodean a la aprobación de una ley, como el grado de deliberación pública que existió sobre la materia, y la aceptación o confianza de la ciudadanía con respecto al Parlamento en el momento de discusión de la ley cuya constitucionalidad se revisa. Una ley que regula una materia a cuya entrada en vigencia ha precedido

17. Se involucran en la interpretación constitucional todos los órganos e instituciones estatales. Incluso organizaciones de la sociedad civil y los particulares pueden interpretar la Constitución. Así se ha postulado, por ejemplo, la teoría de la sociedad abierta de los intérpretes constitucionales.

18. Su exponente más destacado es Jeremy Waldron. 
un amplio debate ciudadano, y aprobada por un Parlamento con altos grados de respaldo y confianza por parte de los electores, gozará de una fortísima presunción de constitucionalidad. Al contrario, una ley aprobada sin deliberación ni información de la materia en la ciudadanía, por un Parlamento con baja aceptación, verá muy debilitada la presunción que le asiste (Ferreres Comella, 1997: 216). En cuanto a la materia, también es posible distinguir diversas intensidades de esta presunción. Así, tratándose de legislación que introduce limitaciones de derechos fundamentales, la presunción se ve debilitada y el examen del juez constitucional habrá de ser más riguroso (Landa, 2000: 129; Zapata Larraín, 2008: 229). Ferreres Comella (1997: 242) sostiene que la presunción llega a invertirse tratándose de legislación que afecta los intereses de grupos social y políticamente vulnerables. ${ }^{19}$

La otra cara de la moneda de la presunción de constitucionalidad de la ley es el principio de interpretación conforme a la Constitución. Carmona Santander explica que, en virtud de principio:

El tribunal debe buscar la interpretación de las normas que permitan resolver, dentro de lo posible, su conformidad con la Constitución; no cabe pronunciarse por la inconstitucionalidad de una norma, si la misma admite, correctamente interpretada, una lectura conforme a la Carta Fundamental (Carmona Santander, 2012: 118).

Para Hesse (1992: 52), el principio de interpretación conforme es el aspecto jurídicofuncional de la premisa de la primacía del legislador en cuanto a la concretización de la Constitución. «En ningún caso debe ser declarada nula una ley cuando la inconstitucionalidad no es evidente, sino que únicamente existen reservas, por serias que puedan ser» (Hesse, 1992: 51). ${ }^{20}$ Explica el autor alemán que el principio de la interpretación conforme hunde sus raíces en el principio de la unidad del ordenamiento jurídico. En función de esta unidad, las leyes emanadas bajo la vigencia de la Ley Fundamental deben ser interpretadas en consonancia con la Constitución. Al pronunciarse el juez sobre esta consonancia, viene a controlar la concretización de la Constitución llevada a cabo por el legislador, a través de una propia concretización de la Constitución y la ley (Hesse, 1992: 51). Sin embargo, advierte que el forzar la aplicación de este principio puede conllevar un riesgo, pues en este caso:

La primacía del legislador democrático se produce a costa de un cambio de significado del contenido de la ley por parte el Tribunal Constitucional; primacía que puede resultar anulada cuando el precio es excesivamente alto, cuando el contenido que, a través de la interpretación conforme, el tribunal da a la ley contiene no ya un minus sino un aliud frente al contenido original de la ley. En este caso, el tribunal interfiere las competencias del legislador con más intensidad incluso en el supuesto de una declaración de nulidad, ya que es él mismo quien conforma positivamente, mientras que,

19. En un sentido relacionado, la teoría de Ely (1980) sobre el papel de la justicia constitucional como refuerzo de la representación y protección de grupos insulares.

20. Llama la atención la coincidencia de esta afirmación con la doctrina de Thayer. 
en el caso de declaración de nulidad, la nueva conformación sigue siendo asunto del legislador (Hesse, 1992: 52).

Otro principio de interpretación constitucional relacionado es el de la corrección funcional. Postulado por Konrad Hesse (1992: 19), importa que, en su estructuración y organización del poder, la Constitución funda competencias, creando así el ámbito de los respectivos cometidos del poder estatal conforme a derecho. El criterio de la corrección funcional determina que si:

La Constitución regula de una determinada manera el cometido respectivo de los agentes de las funciones estatales, el órgano de interpretación debe mantenerse en el marco de las funciones a él encomendadas; dicho órgano no deberá modificar la distribución de las funciones a través del modo y del resultado de dicha interpretación (Hesse, 1992: 47).

El último concepto que desarrollaré es la doctrina de las cuestiones políticas no justiciables o political questions. Se trata de una teoría sobre la competencia de la jurisdicción constitucional que implicará la autorrestricción judicial. Esta doctrina de creación jurisprudencial postula que las facultades que la Constitución ha establecido propias de otros poderes son privativas de estos, y no pueden ser revisadas o interferidas por los jueces en cuanto a la forma de su ejercicio (Haro, 1998: 405). Se trata de una doctrina con respecto a la competencia, en tanto considerado un determinado asunto como «cuestión política» se entiende que el juez constitucional carece de competencia para pronunciarse, por ser materia encomendada por el orden constitucional u otra rama u órgano, por lo que esta es «no justiciable»; es decir, que el órgano jurisdiccional no puede entrar a conocer y decidir. ${ }^{21}$

Definir las cuestiones políticas o delimitar su ámbito de aplicación, parece no ser una tarea posible de realizar en abstracto. Landa reconoce la dificultad de asir el concepto o delimitación de la doctrina, señalando que, para perfilar el alcance de las political questions:

La calificación de un proceso constitucional como político o no, no tiene una definición a priori sino casuística; en la medida que lo político opera con categorías decisionistas, las que están de acuerdo con el Zeitgeist de cada época y país, aunque dentro del marco político y jurídico del régimen democrático y constitucional (Landa, 2000: 114).

Por esta razón señala que, para encontrar luces sobre los límites y posibilidades de esta doctrina, debe recurrirse a la jurisprudencia comparada. En el mismo sentido, se pronuncia Sagüés (2005: 297), quien afirma que "prácticamente nunca las Constituciones determinaron la nómina de las political questions: ellas han sido dibujadas

21. El ámbito que paradigmáticamente queda dentro de lo no justiciable es el relativo a las relaciones internacionales. 
soberanamente por los tribunales y, en última instancia, por las cortes supremas y los tribunales constitucionales de cada país».

Esta doctrina tiene una elaboración mayor a las creaciones doctrinarias o jurisprudenciales antes tratadas. Su desarrollo en la jurisprudencia norteamericana es relevante $y$, en el medio latinoamericano, destaca el tratamiento que ha recibido en Argentina (Landa, 200o: 22; Haro, 1988; 1998; 2002; Nino, 1989; Sagüés, 2005). ${ }^{22}$ El primer antecedente de la doctrina de las cuestiones políticas se encuentra en la famosa sentencia Marbury con Madison, en la que el juez Marshall afirma:

La competencia de la Corte es, solamente, para decidir sobre los derechos de los individuos, no para inquirir cómo el Poder Ejecutivo, o los funcionarios del Poder Ejecutivo, desempeñan deberes en los cuales tienen completa discreción. Cuestiones en su naturaleza política, o las que, por la Constitución o las leyes, están sometidas al Poder Ejecutivo, nunca pueden ser decididas por este Tribunal (Sagüés, 2005: 296).

Ya perfilada en Marbury con Madison, y formulada en el caso Luther con Borden de 1849 (Sentencia de la Corte Suprema de Justicia de Estados Unidos, Luther con Borden U.S. 48, 1849), la doctrina de las cuestiones políticas se utilizó por la Corte Suprema de Estados Unidos en casos en los que rechazó pronunciarse, por tratarse de cuestiones que corresponde resolver a las ramas políticas. La doctrina fue sistematizada por la Corte Warren en el caso Baker con Carr (Sentencia de la Corte Suprema de Justicia de Estados Unidos Baker con Carr U.S. 186, 1962). ${ }^{23}$ El fallo redujo el ámbito de aplicación de la doctrina y la reformuló, estableciendo criterios o elementos para determinar cuándo se está ante una cuestión política no justiciable. La importancia de este fallo es significativa, llegando a afirmar juristas como Loewenstein (1964: 6) que «Baker con Carr constituye una aportación esencial a la teoría y a la práctica del Estado representativo de nuestro tiempo, como a la función de tercer poder, es decir, los tribunales, en el proceso de decision-making». ${ }^{24}$ La sentencia identifica seis factores o elementos para

22. La doctrina de las cuestiones políticas no justiciables tiene larga tradición en Argentina. Se inicia en 1893 con el caso Cullen con Llerena, donde queda establecido que el ejercicio de las facultades privativas y exclusivas de un órgano de poder no son revisables en sede judicial, en virtud del principio constitucional de la división de poderes.

23. El caso trataba del redistritaje para la elección de representantes en el estado de Tennessee, y su relación con la cláusula de igual protección de los derechos. La Constitución de Tennessee señalaba que los distritos legislativos deberían ser revisados cada diez años de acuerdo al censo. Desde 1901 que no se realizaba redistritaje, habiendo cambiado sustantivamente la proporción de la población y, consecuencialmente, afectándose la igualdad política. La defensa en el caso señaló que la distribución de los distritos era una cuestión política. La Corte Warren, restringiendo el ámbito de aplicación de esta doctrina, la reformuló, y sostuvo que el asunto sometido a su conocimiento no calificaba como una cuestión política no justiciable y la corte era competente para conocerla, dando la razón a los demandantes. Resulta notable que la formulación más precisa de la doctrina de las cuestiones políticas no justiciables provenga de una corte famosa por su activismo.

24. Este autor llega a afirmar que este fallo excede en importancia a Brown con Board of Education, por cuanto mientras la última se refiere a los derechos de una minoría, Baker con Carr se refiere a los derechos 
la determinación de la naturaleza política de una determinada cuestión. Una materia no será justiciable cuando la cuestión a decidir cumpla con alguno de los siguientes criterios:

- Cuando se trate de una potestad que la Constitución entrega a otro órgano del Estado, basado en un texto constitucional demostrable.

- Cuando no existan estándares judiciales apropiados para su resolución.

- Cuando nos enfrentemos a la imposibilidad de adoptar una decisión sin una determinación de política previa que no corresponda al ámbito de la discreción judicial.

- Cuando sea imposible que un tribunal decida el caso sin faltar el respeto a que se debe a otros poderes constitucionales.

- Si concurre una necesidad inusual de adhesión incondicional a una decisión política ya adoptada.

- Se trate de una cuestión que puede producir situaciones embarazosas de emitirse varios pronunciamientos por distintos órganos constitucionales (Alonso García, 1981: 288; Figueroa, 2013: 5).

Si la materia sometida a la decisión del tribunal se califica como una cuestión política, entonces el tribunal carece de competencia para resolver dicho asunto y deberá abstenerse de entrar a su conocimiento, autolimitándose. Las decisiones propias de las esferas de competencia de otros órganos del Estado se constituyen en un límite del control judicial, y caen dentro del campo de la responsabilidad política ante el electorado, en función del principio de la separación de poderes.

En Chile, la doctrina de las cuestiones políticas no justiciables ha recibido poca atención. En los escasos trabajos que en nuestro medio se encuentran sobre el tema, se destaca el tratamiento que ha hecho de esta Francisco Zúñiga. El autor la rescata como una vía de manifestación de la autorrestricción judicial que, junto a principios como la presunción de constitucionalidad, considera puede cumplir un rol virtuoso en un escenario que denomina de "panjudicialismo», apostando por «una política democrática practicada por políticos y ciudadanos, en un horizonte republicano de autogobierno del pueblo» (Zúñiga Urbina, 2008: 307). Sostiene que:

El control de constitucionalidad es inidóneo por definición para enjuiciar la constitucionalidad de las "cuestiones políticas", no debiendo confundirse esta noción con el contenido político propio de los conflictos constitucionales que adoptan la forma de conflictos de poder (conflicto de normas o reparto de poderes, que también es conflicto de normas) (Zúñiga Urbina, 2010: 272).

políticos de la totalidad de la población. El tiempo no le daría la razón, pero la afirmación ilustra el impacto de la doctrina de las cuestiones políticas no justiciables en su época. 
También Luis A. Silva Irarrázaval (2016: 232) ha tratado la doctrina de las cuestiones políticas no justiciables, sosteniendo que se trata de una teoría que mantiene hasta hoy relevancia. Para el autor, la doctrina de las cuestiones políticas no justiciables constituye «una prueba que afirma la doble naturaleza de la Constitución, jurídica y política». Esta doble naturaleza, según Silva, importa que la interpretación constitucional no solo corresponde a los tribunales, sino que:

Siempre habrá un ámbito reservado a los intérpretes políticos de la Constitución, al reconocer la naturaleza eminentemente política de una materia constitucional como una condición que inhibe sus pronunciamientos, la Corte Suprema [de Estados Unidos] confirma el diseño del ejercicio del poder estructurado en la Constitución: la separación de los poderes implica un núcleo de autonomía para la interpretación política libre de interferencia y control judicial (Silva Irarrázaval, 2016: 257).

También trata este tema, aunque en un sentido distinto, Juan Colombo Campbell, exministro y expresidente del Tribunal Constitucional. Este parece negar la existencia de las cuestiones políticas no justiciables, señalando que la competencia de los tribunales es de derecho estricto, y que, de existir un conflicto constitucional, este debe ser resuelto por el Tribunal Constitucional, al que estima órgano puramente jurisdiccional (y no político). Para el autor, este es el «único capacitado, por la función intrínseca que desempeña, para determinar los límites de los poderes públicos y autolimitar su ámbito de actuación propio, como consecuencia de ser el intérprete supremo de la constitución» (Colombo Campbell, 2009: 825). No parece temer este autor a una extensión de las atribuciones de la justicia constitucional, ya que señala que, en el marco de la democracia constitucional (sustantiva), «todo conflicto de intereses de relevancia jurídica, incluidos los constitucionales con ingredientes políticos, debe resolverse a través de un debido, justo y oportuno proceso, con el objeto de evitar que se decida por medio de la fuerza». No obstante, parece entreabrir la puerta cuando señala que «debe determinar, en fase de admisibilidad, si el conflicto es de la esfera de lo estrictamente político, en cuyo caso no debe intervenir» (Colombo Campbell, 2009: 816). Sin embargo, niega la politicidad de la labor del juez constitucional cuando señala, a continuación de la afirmación citada, que si el conflicto es de los que la propia carta fundamental ha contemplado dentro del ámbito jurídico constitucional:

Debe precisarse y declararse que son los tribunales constitucionales los que deben decidirlos, ejerciendo en plenitud su jurisdicción, no obstante ser, por su naturaleza, ajenos al sistema político en cuyo ámbito el conflicto se genera. Puedo afirmar enfáticamente en esta parte introductoria que lo político es el conflicto a decidir, pero no el tribunal que lo decide (Colombo Campbell, 2009: 816).

El problema, que escapa aparentemente al autor, es que la línea que distingue aquello que corresponde a lo estrictamente político y aquello que está dentro del ámbito jurídico constitucional es difusa, y precisamente es esto lo que no permite ser enfático en la distinción. 
La no justiciabilidad encuentra un límite en los asuntos que involucran derechos fundamentales. Así se ha considerado desde su formulación en Marbury. Estos constituyen límites que no pueden ser sobrepasados por la justicia constitucional en la consideración de un determinado conflicto como cuestión política no justiciable. De esta forma, si existen derechos de los individuos en juego, la doctrina no aplica. En el contexto del desarrollo actual del constitucionalismo, este límite viene prácticamente a cancelar las posibilidades de aplicación de la teoría. Como advirtiera Nino (1989: 84), la aplicación de la doctrina depende del alcance que se les otorgue a los derechos individuales, y si la concepción que hay de estos es robusta, quedan muy pocas cuestiones en las que los jueces no pueden intervenir, ampliándose considerablemente el ámbito de intervención judicial. En un contexto de expansión o boom de los derechos fundamentales en que los derechos son considerados «valores» que «inundan» toda la vida social, ¿qué problema político no puede ser reformulado como un problema de derechos?

Se trata de una doctrina en franco declive. Sagüés (2005: 299 y ss.) sistematiza las críticas a esta teoría y señala como motivos del debilitamiento los siguientes:

- Su peligrosidad, puesto que se le ha entendido como una anomalía o «excepción al Estado de derecho».

- Su ilogicidad, refiriéndose a la imposibilidad de definir y delimitar qué es una cuestión política no justiciable, considerándosela una categoría práctica y oportunista.

- Su carácter contradictorio, refiriéndose a que es difícil conciliar la tesis de que hay cuestiones políticas «no justiciables», cuando todo el operativo de control judicial de constitucionalidad es, en sí mismo, un operativo de alta política institucional que trabaja sobre el material político de la Constitución.

- La modificación del contexto de vida, refiriéndose a los cambios en el escenario político que han impactado en la delimitación de las cuestiones políticas, como la consolidación del control de constitucionalidad, la idea de la justicia constitucional como intérprete supremo (y en ocasiones único) de la Constitución, la debilitación de la legitimidad del sistema representativo y una mayor conciencia de la necesidad de afirmar los derechos humanos y la demanda de satisfacción de estos por parte de los ciudadanos, quienes, al no lograr satisfacción por parte de los poderes electos, demandan su concretización a los jueces, a los que resulta difícil ya recluirse en la espesura de los asuntos no justiciables.

Se podría agregar a las explicaciones enunciadas una de corte teórico, relacionada con un giro en el paradigma disciplinario de la teoría constitucional: de la mano del desarrollo y expansión del fenómeno del neoconstitucionalismo y la comprensión de los derechos como «valores», la Constitución pasa a expandirse por todo el sistema jurídico, teniendo algo que decir (y los jueces que resolver) con respecto a cualquier asunto sometido a su conocimiento.

Una doctrina como la de las cuestiones políticas no justiciables importa concebir 
a las disposiciones constitucionales como normas que constituyen mínimos a respetar por los poderes públicos, y no máximos a expandir por los jueces constitucionales. En este concepto, el control de constitucionalidad debe ser un control de cumplimiento de dichos límites, que permite espacios de libre configuración a la política, a través de un modelo de "geografía normativa» de relaciones entre la Constitución y la legislación (Bernal Pulido, 2006: 12). ${ }^{25}$ Como señala críticamente Böckenförde (2000: 41 y ss.), si las prescripciones materiales de una Constitución se entienden como un «orden objetivo de valores», esta incluye en sí la pretensión de una validez incondicionada, que se extiende a todos los ámbitos de la vida social, atribuyendo a unas determinadas convicciones político-éticas una validez jurídica general, de modo que ya no garantiza la libertad incondicionadamente a través de una delimitación jurídico-formal, sino solo la que cabe dentro del sistema de valores reconocido por ella: quien se sitúa fuera de este deja de tener derecho a la libertad política. Agrega que esta forma de entender el Estado de derecho infravalora el significado material que tienen las garantías formales y los procedimientos regulados, pues son estos, precisamente, los que amparan y protegen la libertad individual y social, en tanto son un medio de defensa frente a los ataques que se dirigen directamente contra individuos y grupos sociales en nombre de contenidos materiales, o de supuestos valores, establecidos o interiorizados como algo absoluto. $\mathrm{Si}$ se dota a los postulados ético-morales o a los valores materiales de una vinculatoriedad jurídica que va más allá de la garantía de la libertad igual de todos y de las exigencias fundamentales de una vida en común ordenada, la autonomía individual y libertad quedan sometidas al dominio de los que ejercen el monopolio de la interpretación de estos postulados o valores, o que se lo apropian.

\section{Las teorías de la decisión judicial centrada en las virtudes (o un juez constitucional virtuoso fallará virtuosamente)}

Otra forma de aproximarse al problema del control del juez constitucional es aquella que, ante las particularidades de la interpretación constitucional, propone centrarse en el carácter del juzgador y no en el momento de la adjudicación. Su aparición es relativamente reciente y proviene de la filosofía del derecho. En grueso, postula que, si la indeterminación del lenguaje constitucional y la subjetividad del intérprete son insoslayables, el resultado correcto del proceso de interpretación constitucional dependerá más del sujeto que interpreta que de las pautas, teorías o herramientas que se ofrezcan a dicho sujeto.

Su exponente más relevante es Lawrence Solum. La teoría de Solum se denomina «virtue jurisprudence» y busca, en las virtudes éticas, el carácter y la excelencia humana, respuestas a cuestiones como la naturaleza del derecho, del juzgar y el contenido del derecho. Este autor propone abordar el problema de la interpretación constitucional

25. Tomo la expresión del trabajo referenciado. 
con una aproximación areática, ${ }^{26}$ esto es, una teoría que se enfoca en las excelencias y deficiencias de los funcionarios, característicamente los jueces, que desarrollan la práctica de la interpretación constitucional (Solum, 2005: 662, número 9).

Este autor propone una teoría de la decisión judicial centrada en las virtudes, que presenta como alternativa a las teorías que ofrecen parámetros normativos con respecto a cómo ha de realizarse el acto de juzgar. Solum postula que debemos aproximarnos a la decisión judicial, no desde el acto del juzgar, sino desde la persona que juzga.

Distingue entre una teoría de las virtudes débil y una teoría de las virtudes robusta. Señala que, para cualquier teoría normativa de la decisión judicial, se requieren ciertas características o cualidades (virtudes, en sentido amplio del término) que hacen que un juez sea un buen juez (por ejemplo, la «virtud» de la inteligencia teórica, para ser capaz de comprender un material jurídico complejo). Esto es lo que denomina una teoría débil de las virtudes. Esta se centrará en la decisión judicial, es decir, en cómo se juzga «bien», y según el procedimiento utilizado, la decisión contará como «buena» o «correcta». Será desde el acto de juzgar que se derivarán las virtudes que sean necesarias para arribar a una buena o correcta decisión judicial. Luego, lo primario es la corrección del procedimiento de toma de la decisión. Pero una teoría de la decisión judicial centrada en las virtudes es diferente, se trata de una teoría robusta o gruesa. Su centro está en el carácter del juzgador: lo primario es el juez virtuoso, y luego se procede a derivar la noción de la decisión virtuosa.

Solum desarrolla un modelo que da cuenta de lo que significa un «buen» carácter judicial. Primero, enumera los defectos característicos de un «mal» carácter judicial, lo que llama los vicios judiciales: la corrupción, la cobardía cívica, el mal carácter, la incompetencia y la necedad (foolishness). Segundo, desarrolla el tipo de carácter judicial que evitaría estos defectos, indicando que las virtudes judiciales, es decir, aquellas que específicamente operan en el contexto de la decisión judicial. Estas son la templanza, el coraje, el temperamento (entendido como la disposición para reaccionar o enojarse proporcionalmente a la provocación de la situación), la inteligencia (entendida como la excelencia en el entendimiento y la teorización sobre el derecho) y la sabiduría (entendida como una sabiduría práctica aplicada a las elecciones que los jueces deben realizar). Un tercer paso en esta teoría es explorar la virtud de la justicia, preguntándose ¿qué cualidades mentales o intelectuales hacen que un juez sea justo? ¿Qué es la virtud de la justicia? Para Solum, la justicia es la virtud cardinal del acto de juzgar. Sostiene que juez y justicia son independientes, en el sentido de que la justicia es previa a la decisión judicial (la decisión, en si misma, puede ser justa independiente del carácter de quien la tomó). Sin embargo, solo alguien con el carácter adecuado será apto para idear soluciones justas para los «casos difíciles».

Solum estructura su teoría de la decisión judicial centrada en la virtud, relacionando carácter judicial virtuoso con decisión judicial correcta:

26. Arête es una palabra griega que significa excelencia. 
- Una virtud judicial es la natural disposición mental o la voluntad que, presente junto a las demás virtudes judiciales, confiablemente dispone a quien posee esta virtud a tomar decisiones justas. Las virtudes judiciales incluyen, pero no se limitan, a la templanza, el coraje, el buen temperamento, la inteligencia, la sabiduría y la justicia.

- Un juez virtuoso es un juez que posee las virtudes judiciales.

- Una decisión virtuosa es la decisión tomada por un juez virtuoso, actuando desde las virtudes judiciales en las circunstancias que son relevantes para la decisión.

- Una decisión conforme a derecho es la decisión que tomará, por regla general, un juez virtuoso, atendidas las circunstancias relevantes para la decisión.

- Una decisión justa es idéntica a una decisión virtuosa (Solum, 2003: 198).27

La tesis central de esta teoría es que para que los jueces tomen decisiones virtuosas deben ser virtuosos, de modo que los jueces deben seleccionarse en base a poseer (o tener el potencial de adquirir) las virtudes judiciales (Solum, 2005), pues esto permitirá que tomen decisiones justas tanto en los casos en que nuestro sentido de la justicia se corresponde con el resultado exigido por el derecho (justice as lawfulness) como en aquellos casos en que ello no sucede y el juez recurre a la equidad (justice as fairness). ${ }^{28}$

Para Solum es en los llamados «casos difíciles» donde su teoría demuestra su mayor fortaleza. En los casos sencillos también se requieren virtudes para reconocer el resultado requerido por el derecho. Pero en los casos difíciles, donde es imposible encontrar una única respuesta correcta en el derecho o en que en forma intencional se otorga al juez discrecionalidad, ${ }^{29}$ la teoría de la decisión judicial centrada en las virtudes permitiría explicar por qué puede existir más de una decisión correcta. Diversos jueces podrán tomar distintas decisiones. Si son jueces virtuosos, podrán tomar decisiones correctas (virtuosas), porque actúan desde la virtud. No obstante, si la decisión está tomada motivada por un vicio (por ejemplo, la corrupción), la decisión será incorrecta, aun cuando sea conforme a derecho. La teoría centrada en las virtudes explica, en sus términos, que dos jueces virtuosos pueden llegar a decisiones diferentes, incluso si ambos actúan desde las virtudes. En los casos en que el juez no actúa desde las virtudes, sino que, desde motivaciones viciosas como la corrupción, o el desprecio por el derecho, entonces una decisión discrecional será incorrecta, incluso si ese mismo resultado podría haberse aceptado si hubiera sido producto de la decisión de un juez virtuoso.

Solum manifiesta que su teoría ofrece respuesta para los casos en que el resultado requerido por la aplicación del derecho no se corresponde con nuestro sentido de la justicia. En estos casos, afirma, una decisión virtuosa es la guiada por la virtud de la

27. La traducción es nuestra.

28. Solum advierte expresamente que la expresión no está utilizada en el sentido que le da Rawls.

29. Pone como ejemplo el estándar del interés superior del niño, niña o adolescente en los casos de cuidado personal. 
equidad. Lo característico de la equidad es que consiste en una desviación de las normas animada por las circunstancias particulares del caso concreto. La equidad viene a corregir a la universalidad de la ley cuando su aplicación en un caso particular deviene en un resultado injusto. Para Solum, solo un juez virtuoso puede practicar la equidad y, por esto, afirma que la teoría centrada en las virtudes ofrece una aproximación distintiva a los casos que involucran consideraciones de equidad. Otras teorías normativas de la decisión judicial tienen dificultades para explicar por qué debe existir una práctica de la equidad. Una teoría centrada en las virtudes plantea que la complejidad y variedad de los casos que presenta la realidad excede nuestra capacidad de dictar reglas generales. La solución es confiar la decisión a jueces virtuosos que puedan producir una decisión que se ajuste al caso particular (Solum, 2003: 206). Esta teoría normativa ofrecería explicación y justificación de la práctica de la equidad, punto en que muchas de las otras teorías tropiezan.

En el ámbito latinoamericano, el argentino Juan Bautista Etcheverry sigue la teoría de Solum y aborda el problema de la discrecionalidad judicial tomando como base la teoría de la decisión judicial centrada en las virtudes. Etcheverry (2014: 153) comienza reconociendo que los jueces ocupan «un lugar especialmente relevante dentro de los poderes políticos» y expresa que, si bien el derecho es siempre indeterminado, y la discrecionalidad judicial no es solo inevitable, sino que puede también ser deseable, esto no significa que ante la indeterminación el juez pueda actuar arbitrariamente. Cuando el juez decide dentro de la «zona de penumbra», este actúa de forma discrecional, pero de la existencia de más de una solución posible y/o correcta (Etcheverry, 2014: 156) ${ }^{30}$, no se sigue que no existan soluciones incorrectas.

Etcheverry (2014: 153) concibe la discrecionalidad judicial como una elección no arbitraria y limitada: sus límites sustanciales son que esta sea correcta y justa, en la medida que todos los ordenamientos jurídicos tienen esa pretensión, aunque reconoce que este es un límite demasiado amplio, ya que existen múltiples concepciones acerca de lo correcto, razonable o justo. También considera como límite a la discrecionalidad la exclusión de la arbitrariedad, ya que la decisión judicial ha de estar siempre justificada, y especificándolo afirma que «en ningún caso y bajo ninguna excepción puede pretender resolverse un caso atribuyéndose a una norma un fin extremadamente injusto o contrario al núcleo de los derechos humanos» (Etcheverry, 2014: 160).

El autor señala que, inevitablemente, los jueces, al decidir, crean derecho. Frente a esto propone una aproximación centrada en la figura de la persona del juez desde la teoría de las virtudes éticas, indagando con respecto a las disposiciones o aptitudes que se han de tener para desempeñar correctamente la función jurisdiccional. Para este autor, la prudencia es la virtud fundamental de la judicatura y «una presentación de la virtud de la prudencia alcanza para mostrar la potencialidad de las teorías de la deci-

30. Señala Etcheverry que «no es imposible que, una vez valorados todos los elementos objetivos que han de tenerse en cuenta a la hora de decidir un caso, los jueces terminen viéndose obligados a optar libremente entre alternativas valiosas y razonables». 
sión judicial centradas en las virtudes para ofrecer pautas positivas de decisión judicial discrecional» (Etcheverry, 2014: 161).

En un sentido algo diferente, pero relacionado y con menos precisión conceptual, Mora Restrepo (2009; 2014: 530 y ss.) propone, como remedio a una interpretación activista de la Constitución colombiana, ${ }^{31}$ enfrentar lo que denomina el problema del talante moral del intérprete constitucional. Frente a lo que considera un abuso de conceptos como la zona de penumbra (Hart) o ductilidad del derecho (Zagrebelsky), postula que:

Hace parte del oficio del jurista discernir, comprender y determinar la justicia en los casos concretos, sobre la base de un derecho que se erige como fundamental, que, aunque contenga cláusulas abiertas, posee también de base aquel respaldo, absoluto, en los núcleos indisponibles y objetivos que emanan de la dignidad humana (Mora Restrepo, 2014: 542).

Llama a una «defensa de la interpretación constitucional» y propone un retorno a las reglas de justificación que permitirían un control de la argumentación de los jueces constitucionales, tanto en lo relativo a la lógica interna empleada por el fallador, como el valor material o de fondo de las propias premisas empleadas en el fallo. Pero más relevante considera lo que denomina el talante moral de quienes ocupan el cargo y asumen la tarea de ser intérpretes y garantes de la Constitución. Señala que este problema enfrenta la cuestión de la condición moral del oficio de los jueces y resalta «la exigencia, en el fallador mismo, de condiciones que hagan posible la corrección y la justicia concreta». Estas condiciones suponen un juez constitucional «que se sitúa ante los casos con ese deseo siempre latente, intenso y firme, de querer la justicia por encima de cualquier consideración ideológica o personal» (Mora Restrepo, 2014: 546). ${ }^{32}$ Se trata, entonces, de que la virtud de la justicia sea el principio rector de su oficio.

\section{Posibilidades y limitaciones de la aproximación al problema del control del juez constitucional desde la confianza en las virtudes: El catálogo de virtudes y el modelo de juez constitucional ideal}

Como se ha visto, el problema de la limitación del poder de los jueces constitucionales

\footnotetext{
31. Mora Restrepo no utiliza el término activista, sin embargo, creo que se refiere a esa actitud cuando denuncia ideologización en los fallos constitucionales y que «ante ciertos temas o hechos de gran relevancia, algunos jueces utilizan su posición de poder (inmenso) para sacar partido en algún sentido», fundando la afirmación en fallos de la Corte Constitucional colombiana en temas como aborto, objeción de conciencia y matrimonio igualitario. Denuncia que «los jueces constitucionales, en muchos casos, han venido a suplantar a la Constitución mediante tesis que logran abrirse paso en las sentencias constitucionales, las cuales son presentadas a través de artilugios interpretativos de todo tipo» y que «existen y han existido pseudointerpretaciones constitucionales, oficiadas por el poder de turno, por mayorías episódicas de una Corte o que, en efecto, existen jueces inescrupulosos que ofician con toga pero que, soterradamente, manejan su propia agenda personal o grupal para imponer determinadas ideologías».
}

32. En cursivas en el texto original. 
ha sido abordado por la doctrina de un modo principalmente normativo, a través del desarrollo de teorías que vienen a ofrecer al juez constitucional un modelo a seguir. He denominado a este modo de aproximación al problema la perspectiva de confianza en las virtudes, para denotar que se funda en la confianza en que las pautas o modelos normativos serán suficientes para persuadir que el juez actúe virtuosamente.

Dentro de esta aproximación, he identificado tres categorías de trabajos. Primero, los trabajos que ofrecen un modelo de juez constitucional ideal, identificando un perfil de juez constitucional y una enunciación de los valores que este ha de realizar. Esta aproximación confía en que el juez constitucional, por el hecho de ser tal, ha de cumplir con el perfil indicado, sin desarrollar el cómo se han de concretar en la realidad este perfil o qué hacer si el juez en los hechos no cumple con los valores identificados. Un segundo grupo de trabajos se refiere a la construcción de herramientas interpretativas para la adjudicación constitucional que un juez constitucional, que adopte las virtudes pasivas, habrá de utilizar. Estas herramientas son el principio de autorrestricción judicial, el principio de deferencia razonada, el principio de corrección funcional, la presunción de constitucionalidad de los actos del legislador y la teoría de las cuestiones políticas no justiciables. Finalmente, el tercer grupo identificado agrupa a los trabajos que proponen centrarse en la virtud personal del sujeto juez constitucional, su carácter y talante moral. Esto, se sostiene, eximiría de la necesidad de controlar su labor en el momento de la adjudicación, ya que un juez virtuoso necesariamente juzgará virtuosamente.

Los modelos normativos ofrecidos al juez constitucional para limitar su poder identifican un ejercicio virtuoso de la jurisdicción constitucional con un ejercicio restrictivo de sus competencias y su rol en el sistema democrático. Esas pautas normativas se explican por la comprensión que se tiene de la labor del juez constitucional, la que se ve determinada por el constitucionalismo y el principio fundamental de la separación de poderes, dentro del cual no encuentra su lugar y, sin embargo, determina su actuación. El modelo de separación de poderes no solo es descriptivo, sino que tiene una relevante dimensión prescriptiva. Conforme a este principio es que el juez constitucional se entiende a sí mismo, concibe principios de auto control, y se elabora por la doctrina el modelo ideal de juez constitucional y las virtudes con que ha de enfrentarse la tarea de la interpretación constitucional.

Poner toda la esperanza en modelos ideales o confiar en la virtud representa un acto de fe que acarrea importantes peligros en un sistema democrático. Los mecanismos de control revelan su importancia precisamente ante la ausencia de conciencia democrática y moderación. El control se pone en marcha cuando, de hecho, se genera un desequilibrio en el ejercicio del poder; cuando nos enfrentamos a la parcialidad, el activismo judicial desatado o una jurisdicción constitucional que actúa con espíritu corporativo o gremial. En otras palabras, no es el buen juez constitucional, el ideal, el que hace necesario el control, sino el mal juez constitucional.

Esto no significa que los modelos normativos no tengan utilidad. Sirven para evaluar la legitimidad de la labor del juez constitucional. Para calificar si en un caso deter- 
minado el ejercicio del poder depositado en el juez constitucional ha sido adecuado, necesitamos contrastar esto con exigencias normativas que nos indiquen qué es un ejercicio adecuado de este poder. En otras palabras, para poder identificar a un mal juez constitucional, es imprescindible tener modelos normativos que indiquen qué es un buen juez constitucional. Identificar las exigencias normativas que se dirigen al juez constitucional será útil, ya sea que la evaluación se realice por un órgano del Estado que tiene una potestad de control sobre el juez constitucional, ya sea que la ciudadanía evalúe y se forme opinión pública con respecto al ejercicio del poder, o ya sea que el propio juez constitucional realice una autoevaluación de cómo ejerce o debería ejercer su poder. ${ }^{33}$

Además, una vez que se formulan y se consolidan, los modelos normativos pasan a formar parte de precomprensiones del intérprete constitucional, a las que se recurrirá en el momento de la adjudicación, pudiendo resultar en una autolimitación del poder. Un juez que se toma en serio los compromisos de la democracia constitucional con la regla de la mayoría, que adscriba o simpatice con un constitucionalismo político o democrático, probablemente hará de estas virtudes judiciales parte de su repertorio de argumentos. El punto es que un juez activista, comprometido con otras visiones normativas de la democracia, puede escoger otros argumentos interpretativos y modelos normativos de interpretación que no son necesariamente incompatibles, pero sí entran en tensión con las virtudes pasivas, como podría ser el principio favor libertatis o la teoría de la Constitución viva, que requerirían del juez un entendimiento más extensivo o creativo de sus competencias, por poner algunos ejemplos. Finalmente, como modelos normativos que son, se tratan de una cuestión de opción para el juez constitucional y no pueden considerarse controles efectivos.

Con respecto a las virtudes pasivas, ya he explicado que estas son generalmente caracterizadas como principios. Esto nos enfrenta con lo que denominaré la aporía de los principios de autolimitación. Resulta paradojal que, frente al riesgo de una eventual usurpación de funciones por parte de los jueces constitucionales, realizando una actividad creadora que conforme a la Constitución corresponde al legislador, se ofrezcan como solución principios que no encuentran justificación directa o explícita en el ordenamiento constitucional.

Si el problema de la justificación de la actividad del juez constitucional se debe, en parte, a la escasa densidad de las normas constitucionales, cuyo contenido para el caso dependerá de una interpretación constitucional indefectiblemente ligada a las precomprensiones del intérprete y su subjetividad, no se ve cómo el ofrecer un "principio» a incorporar a su argumentación (un nuevo elemento a su precomprensión) puede resolver la cuestión. El déficit de justificación podrá predicarse también de este remedio (la herramienta interpretativa del principio de autorrestricción, o el concepto que sea), toda vez que su utilización dependerá de si el juez constitucional decide o no echar mano de ella en su argumentación. En este sentido, las palabras del juez del Tri-

33. De ahí el carácter testimonial de muchos trabajos sobre la materia. 
bunal Constitucional alemán, Rudolf Mellinghoff, son ilustrativas de las limitaciones que doctrinas como las estudiadas tienen, particularmente vistas desde los sistemas concentrados:

Tomando como referencia la jurisprudencia de la Corte Suprema de los Estados Unidos, a veces se menciona el principio de la autolimitación judicial (judicial selfrestraint) para conjurar el peligro de un "Estado jurisdiccional" bajo la dirección del Tribunal Constitucional. Sin embargo, este término general y sin matices sirve apenas para describir el problema, y no permite una delimitación de los cometidos de la jurisdicción y legislación. El mandato de la autolimitación judicial carece de contenido y, a menudo, tiene como único propósito caracterizar decisiones incómodas como extralimitación. Cualquier limitación por mandato propio no contaría con un fundamento constitucional ni reflejaría el cometido del Tribunal Constitucional. Si de hecho lo hace, y decide autolimitarse, el resultado será efectivamente una disminución de la intensidad del resultado de su acción, pero no un remedio eficaz frente al riesgo que se quiere conjurar. Este debe hacerse cargo de las obligaciones que la Constitución le confiere y no está facultado a apoyarse en sus competencias para renunciar a la evaluación de casos jurídico-constitucionales problemáticos (Mellinghoff, 2011: 495).34

Y agrega que lo mismo se aplica a la doctrina de las cuestiones políticas (Sierra y Mac-Clure, 2011: 262). ${ }^{35} \mathrm{El}$ remedio es tal solo si funciona cuando el juez, precisamente, no actúa autolimitándose.

En cuanto al modelo de juez constitucional ideal o juez virtuoso, desde luego, es deseable que los jueces constitucionales sean justos, prudentes y comprometidos con los derechos humanos. Desde una moral republicana, se puede exigir que sean buenos ciudadanos, comprometidos con la democracia. O se puede, desde una moral liberal, pedirles un compromiso con la autonomía (Nino, 1991: 128), ${ }^{36}$ por poner algunos ejemplos. Sin embargo, la enumeración de un catálogo más o menos amplio de virtudes a concretar por parte del juez constitucional enfrenta el desafío de acordar cuáles son las virtudes exigidas, y con ello el problema del desacuerdo. En una sociedad plural, los ciudadanos probablemente discrepemos tanto en el catálogo de virtudes a exigirles como en la importancia o prelación de estas. Por ejemplo, es claro que, en el paradigma del Estado constitucional de derecho, un juez constitucional debe ser un demócrata - estar comprometido con la regla de la mayoría y la soberanía popular- y que debe ser un convencido de la dignidad humana y la vigencia de los derechos fundamentales. Pero, puestos a escoger, ¿preferiremos que sea un juez activista en respeto de los derechos o deferente con respecto al proceso democrático? Esta cuestión nos lleva de vuelta

34. Los destacados son nuestros.

35. Han advertido sobre esto en nuestro medio, refiriéndose principalmente a la deferencia, Sierra y Mac-Clure, quienes llegan a afirmar que esto aumenta la falta de certeza jurídica en materia de derechos.

36. Como la propuesta de Nino, que señala que los jueces constitucionales deben actuar para garantizar que las leyes no sean «perfeccionistas», es decir, que impongan un ideal de virtud sin respetar la libertad de cada persona para determinar su propio ideal de vida. 
al problema de la tensión de la democracia constitucional y de las diversas formas de concebir el constitucionalismo. Y luego, está el problema de qué hacer cuando las virtudes no se verifican en su actuación, es decir, qué respuesta si es que hay alguna, ofrece el sistema institucional para el mal juez constitucional.

\section{Conclusiones}

Definir doctrinariamente un perfil de juez constitucional ideal, y plantear doctrinas de autocontrol, pueden ser relevante como elementos de interpretación constitucional o como parámetros para la evaluación del juez constitucional. Sin embargo, como aproximación al problema de la limitación del poder del juez constitucional, resulta insuficiente. El autocontrol podrá traducirse en una limitación o renuncia al ejercicio del poder, ya sea del Tribunal Constitucional en su conjunto, o del juez constitucional individualmente considerado, pero no son controles efectivos. Además, todo autocontrol supone una conducta proba, moderada, y una vigilante conciencia democrática por parte de los jueces constitucionales. Cuando estas condiciones existen, las oportunidades para hacer efectivos los controles, del tipo que sean, son escasas en número y en importancia. Un mecanismo de control solo será tal cuando la limitación del poder no dependa de la voluntad del juez constitucional y se verifique incluso en contra de esta. El control es tal cuando el poder encuentra un freno en el poder, recordando la famosa expresión de Montesquieu.

De este modo, la aproximación de la confianza en las virtudes resulta insuficiente como herramienta de control, y un voto de confianza ingenuamente optimista. Un verdadero abordaje del problema de la limitación del rol del juez constitucional en una democracia, si esperamos que su poder se someta a un control efectivo, habrá de apoyarse necesariamente en arreglos institucionales.

\section{Referencias}

Alonso García, Enrique (1981). «El Tribunal Burger y la doctrina de las "political questions" en los Estados Unidos». Revista Española de Derecho Constitucional, 1 (1): 287-299.

Álvarez Miranda, Ernesto y Carolina Canales Cama (2009). «La elección del juez constitucional». En Ernesto Álvarez Miranda (editor), Constitución y proceso: Libro homenaje a Juan Vergara Gotelli. Lima: Jurista Editores, Tribunal Constitucional.

Azuela Gürtrón, Mariano (2009). «El juez constitucional». En Edgar Corzo Sosa, (coordinador), I Congreso Internacional sobre Justicia Constitucional. México: Universidad Autónoma de México, Instituto de Investigaciones Jurídicas. Disponible en bit.ly/3yoyS96.

BARAK, Aharon (2006). The judge in a democracy. Nueva Jersey: Princeton University Press. 
Bello Hutt, Donald (2017). «Contra la supremacía judicial en la interpretación de la Constitución». Revus Journal for Constitutional Theory and Philosophy of Law, 33. Disponible en bit.ly/2UvMilc.

Bernal Pulido, Carlos (2006). El neoconstitucionalismo a debate. Bogotá: Universidad Externado de Colombia.

BICKEL, Alexander (1986). The least dangerous branch. The supreme court at the bar of politics. New Haven: Yale University Press.

Blanco VAldÉs, Roberto L. (1994). El valor de la Constitución. Madrid: Alianza.

BöCKENFÖRDE, Ernst Wolfgang (200o). Estudios sobre el Estado de derecho y la democracia. Trad. Por Rafael de Agapito Serrano. Madrid: Trotta.

Caballero, José Antonio (2010). «La rendición de cuentas en los poderes judiciales». En Mauricio Merino, Sergio López-Ayllón y Guillermo Cejudo (coordinadores), La estructura de la rendición de cuentas en México. México: Instituto de Investigaciones Jurídicas Universidad Autónoma de México.

Carbonell, Flavia, Rodrigo Coloma y Raúl Letelier (2011). Principios jurídicos: Análisis y crítica. Santiago: Universidad Alberto Hurtado, Abeledo Perrot y Thomson Reuters.

Carmona Santander, Carlos (2012). «Autorrestricción en el Tribunal Constitucional chileno». Derecho y Humanidades, 19: 75-128. Disponible en bit.ly/36U7ihu.

Cea Egaña, José Luis (2003). «Perfil axiológico, independencia y responsabilidad del juez constitucional». Revista Ius et Praxis, 9, (2): 187-199. Disponible en bit. ly/36N46nY.

-. (2010). «El juez constitucional en Chile». En Víctor Bazán (coordinador), Derecho procesal constitucional americano y europeo. Tomo I. Buenos Aires: Abeledo Perrot

Cодомво Campbell, Juan (2009). «La judiciabilidad de las cuestiones políticas». Anuario de Derecho Constitucional Latinoamericano, 15: 815-826.

Соцомво Murúa, Ignacio (2012). «Una aproximación hermenéutica al activismo judicial». La Ley. Suplemento de Derecho Constitucional: 32-42. Disponible en bit. ly/3wTtLWK.

Conferencia Iberoamericana de Justicia Constitucional (2006). «El juez constitucional». En V Conferencia Iberoamericana de Justicia Constitucional. Madrid: Imprenta Nacional del Boletín Oficial del Estado. Disponible en bit.ly/3kzpp4C.

Courtis, Christian (2006). Observar la ley. Ensayos sobre metodología de la investigación jurídica. Madrid: Trotta.

DíAz Bravo, Enrique (2012). «Desarrollo histórico del principio de separación de poderes». Revista de Derecho (Universidad del Norte, Barranquilla, Colombia), 38: 240270. Disponible en bit.ly/zzhRamf.

ELY, John (1980). Democracy and distrust. Cambridge: Harvard University Press.

EtcheVERrY, Juan Bautista (2014). «Discrecionalidad judicial: Causas, naturaleza y límites». Teoría y Derecho, 15: 148-171.

Ferreres Comella, Víctor (1997). Justicia constitucional y democracia. Madrid: Centro de Estudios Políticos y Constitucionales. 
FigueroA, Dante (2013). «La doctrina estadounidense de la cuestión política: Etiología, axiología y perspectivas para Latinoamérica». IUS Doctrina, 9: 1-31.

HäBERLE, Peter (2008a). «La jurisdicción constitucional en la sociedad abierta». En Eduardo Ferrer Mac-Gregor y Arturo Zaldívar (coordinadores), La ciencia del derecho procesal constitucional. Estudios en homenaje a Héctor Fix-Zamudio en sus cincuenta años como investigador del derecho. México: Universidad Autónoma de México, Instituto Mexicano de Derecho Procesal Constitucional, Marcial Pons.

-. (2008b). «La sociedad abierta de los intérpretes constitucionales: Una contribución para la interpretación pluralista y "procesal” de la Constitución». Academia. Revista sobre Enseñanza del Derecho, 6 (11): 29-61. Disponible en bit.ly/3eGRovw.

Haro, Ricardo (1988). «Las cuestiones políticas: ¿Prudencia o evasión judicial?». En Estudios en homenaje al doctor Héctor Fix-Zamudio en sus treinta años como investigador de las ciencias jurídicas. Tomo I. México: Universidad Autónoma de México, Instituto de Investigaciones Jurídicas.

-. (1998). «El control jurisdiccional y las “cuestiones políticas": Nuevas perspectivas». $V$ Congreso Iberoamericano de Derecho Constitucional. México: Universidad Autónoma de México, Instituto de Investigaciones Jurídicas.

-. (2002). Constitución, poder y control. México: Universidad Autónoma de México, Instituto de Investigaciones Jurídicas.

Hesse, Konrad (1992). Escritos de derecho constitucional. Trad. por Pedro Cruz Villalón. Madrid: Centro de Estudios Constitucionales.

Kramer, Larry (2011). Constitucionalismo popular y control de constitucionalidad. Trad. por Paola Bergallo. Madrid: Marcial Pons.

-. (2012). "Judicial supremacy and the end of judicial self-restraint». California Law Review, 100 (3): 621-634.

LANDA, Cesar (2000). «Justicia constitucional y political questions». Pensamiento Constitucional, 7 (7): 110-140. Disponible en bit.ly/3BlYrmV.

-. (2004). «La elección del juez constitucional». Revista Latinoamericana de Derecho, $1(2): 127-162$.

LinARES, Sebastián (2008). «Sobre el ejercicio democrático del control judicial de las leyes». Isonomía, 28: 149-186. Disponible en bit.ly/2V29wch.

Loewenstein, Karl (1964). «La función política del Tribunal Supremo de los Estados Unidos (comentario en torno al caso Baker con Carr)». Revista de Estudios Políticos, 133: 5-40. Disponible en bit.ly/3601ENU.

Martínez Estay, José Ignacio (2014). «Autorrestricción, deferencia y margen de apreciación. Breve análisis de sus orígenes y de su desarrollo». Estudios Constitucionales, 12, (1): 365-396. Disponible en bit.ly/3iv8KMR.

-. (2015). «La deferencia del Tribunal Constitucional respecto del juez de la gestión pendiente en la cuestión de inaplicabilidad». Estudios Constitucionales, 13 (1): 237270. Disponible en bit.ly/2V2M1iZ.

Mellinghoff, Rudolf (2011). «Los tribunales constitucionales entre la autolimitación 
judicial y la injerencia político-constitucional». Anuario de Derecho Constitucional Latinoamericano, 17: 485-501.

Mora Restrepo, Gabriel (2009). Justicia constitucional y arbitrariedad de los jueces: Teoría de la legitimidad en la argumentación de las sentencias judiciales. Buenos Aires: Marcial Pons.

-. (2014). «El drama y la gloria de la interpretación constitucional». Revista Facultad de Derecho y Ciencias Políticas, 44 (121): 527-550.

Nino, Carlos Santiago (1989). Consideraciones sobre la dogmática jurídica. México: Universidad Nacional Autónoma de México, Instituto de Investigaciones Jurídicas.

-. (1991). «Los fundamentos del control judicial de constitucionalidad». Cuadernos y Debates, Centro de Estudios Constitucionales, 29: 97-135.

Nogueira Alcalá, Humberto (2004). «La independencia y responsabilidad del juez constitucional en el derecho constitucional comparado». Revista Iberoamericana de Derecho Procesal Constitucional, 1: 61-91.

Posner, Richard A. (2012). «The rise and fall of judicial self-restraint». California Law Review, 100 (3): 519-556. Disponible en bit.ly/3wO2NzK.

Poyanco Bugueño, Rodrigo Andrés (2013). «Los jueces constitucionales, la política y la deferencia judicial». Derecho Público Iberoamericano, 2: 67-101. Disponible en bit. ly/36QnFM8.

Rohrmoser Valdeavellano, Rodolfo (2002). «Corte de Constitucionalidad: La jurisdicción constitucional en Guatemala». En Edgar Corzo Sosa y Juan Vega Gómez (coordinadores), Tribunales y Justicia Constitucional. Memoria del VIII Congreso Iberoamericano de Derecho Constitucional. México: Universidad Autónoma de México, Instituto de Investigaciones Jurídicas.

Rufino do VAle, André (2017). La deliberación en los tribunales constitucionales. Madrid: Centro de Estudios Políticos y Constitucionales.

SAGüÉs, Néstor Pedro (2005). «Reflexiones sobre la doctrina de las cuestiones políticas no justiciables, a propósito de la "coalición” contra Irak». Revista Iberoamericana de Derecho Procesal Constitucional, 4: 295-312.

SIERRA, Lucas y Lucas Mac-Clure (2011). Frente a la mayoría: Leyes supramayoritarias y Tribunal Constitucional en Chile. Santiago de Chile: Centro de Estudios Públicos, Corporación de Estudios para Latinoamérica, Instituto Libertad y Desarrollo, Proyectamérica.

Silva Gallinato, María Pía (2014). «El principio de deferencia razonada y las actuaciones de las Cámaras durante la tramitación de la ley. Examen de una sentencia del Tribunal Constitucional». Revista de Derecho Público, 81: 141-153. Disponible en bit. ly/3iuc3nE.

Silva Irarrázaval, Luis Alejandro (2012). «¿Es el Tribunal Constitucional el supremo intérprete de la Constitución?». Revista de Derecho (Pontificia Universidad Católica de Valparaíso), 38: 573-616. Disponible en bit.ly/3rqoZvN. 
-. (2016). «Las cuestiones políticas: ¿Una doctrina sobre los límites del Poder Judicial? El caso de Estados Unidos». Estudios Constitucionales 14, (2): 231-262. Disponible en bit.ly/36Uajii.

Solum, Lawrence (2003). «Virtue Jurisprudence: A virtue-centred theory of judging». Metaphilosophy, 34 (1-2): 178-213. Disponible en bit.ly/3kARF6U.

-. (2005). «Judicial selection: Ideology versus character». Cardozo Law Review, 26: 659-689. Disponible en bit.ly/3rn4naJ.

Stone SweEt, Alec (2000). Governing whit judges. Constitutional politics in Europe. Nueva York: Oxford University Press.

ThaYer, James (1893). «The origin and scope of the American doctrine of constitutional law». Harvard Law Review, 7 (3): 129-156. Disponible en bit.ly/3eGJ1QB.

ZAGREBELSKY, Gustavo (2008). «El juez constitucional en el siglo XXI». Revista Iberoamericana de Derecho Procesal Constitucional, 10: 249-268. Disponible en bit. ly/3wYkTz4.

Zapata LARRAÍn, Patricio (2008). Justicia constitucional: Teoría y práctica en el derecho chileno comparado. Santiago: Jurídica de Chile.

ZúÑIga Urbina, Francisco (2008). "Control judicial de los actos políticos. Recurso de protección ante las "cuestiones políticas"». Revista Ius et Praxis, 14 (2): 271-307. Disponible en bit.ly/2W5zr3d.

-. (2010). «Tribunal Constitucional. Problemas de posición y legitimidad en una democracia constitucional». Pensamiento Constitucional, 14 (14): 257-289. Disponible en bit.ly/3kForRe.

\section{Sobre la autora}

Tania Busch Venthur es abogada y licenciada en Ciencias Jurídicas y Sociales por la Universidad de Concepción, magíster en Ciencias Jurídicas y doctora en Derecho por la Pontificia Universidad Católica de Chile. Actualmente, es profesora asistente del área de Derecho Público en la Facultad de Derecho de la Universidad Andrés Bello, Chile. Su correo electrónico es tania.busch@unab.cl. (D) https://orcid.org/000 o-0002-6943-2595. 
La Revista de Derecho Público es publicada desde 1963 por el Departamento de Derecho Público de la Facultad de Derecho de la Universidad de Chile. Aparece dos veces al año. Su propósito es la difusión de los avances del derecho público nacional e internacional y la socialización de artículos de investigación inéditos de la comunidad académica nacional e internacional.

DIRECTORA

Ana María García Barzelatto

SECRETARIO DE REDACCIÓN

Felipe Peroti Díaz

fperoti@derecho.uchile.cl

SITIO WEB

revistaderechopublico.uchile.cl

CORREO ELECTRÓNICO

publico@derecho.uchile.cl

LICENCIA DE ESTE ARTÍCULO

Creative Commons Atribución Compartir Igual 4.o Internacional

La edición de textos, el diseño editorial

y la conversión a formatos electrónicos de este artículo

estuvieron a cargo de Tipográfica

www.tipografica.io 